\title{
SYNTHESIS, SCREENING OF NOVEL 1-SUBSTITUTED-3-(4-0X0-2-PHENYLQUINAZOLIN- 3(4H)-YL) UREA AND THIOUREA ANALOGUES AS POTENT ANTIBACTERIALS
}

\author{
SANDHYA R. DHOKALE1, SNEHAL R. THAKAR', DEEPALI A. BANSODE2*, KAKASAHEB R. MAHADIK ${ }^{3}$
}

1,2Department of Pharmaceutical Chemistry, Poona College of Pharmacy, Bharati Vidyapeeth (Deemed to be University), Pune 411038, Maharashtra, India, ${ }^{3}$ Principal, Poona College of Pharmacy, Bharati Vidyapeeth (Deemed to be University), Pune 411038, Maharashtra, India Email: deepali_mhaske@rediffmail.com

Received: 24 Aug 2019, Revised and Accepted: 11 Oct 2019

\begin{abstract}
Objective: The proposed study is an attempt to determine antibacterial activity of synthesized novel 1-substituted-3-(4-oxo-2-phenylquinazolin$3(4 \mathrm{H})-y \mathrm{l}$ ) urea and thiourea analogues as potent antibacterials against $S$. aureus and E. coli bacteria.

Methods: The present study reports new series of 1-substituted-3-(4-oxo-2-phenylquinazolin-3(4H)-yl) urea and thiourea derivatives as potent antibacterial agents. Reagents used in the present study were of synthetic grade and solvents were used after distillation. Novel quinazolinone analogues were synthesized by considering substitution pattern, characterization of the synthesized analogues was performed using various techniques like Thin layer chromatography, Melting point, Infrared spectroscopy, Proton NMR spectrometry and Mass spectrometry. TLC of the synthesized analogues was carried out by using (toluene: methanol in the ratio 2:1), melting point was found by open capillary method, IR spectrum was recorded on JASCO V-530, 1H NMR was recorded on Bruker Avance Spectrometer and Mass spectra were obtained from G6460A, triple quadrupole/MS/MS system. In vitro antibacterial activity was performed against S. aureus and E. coli.

Results: Six derivatives of quinazolinone analogues were synthesized. The structures of 1-substituted-3-(4-oxo-2-phenylquinazolin-3(4H)-yl) urea and thiourea derivatives were confirmed by physical and spectral analysis. Synthesized molecules showed $R f$ of $0.45-0.80$ in toluene: methanol mobile phase, melting point was carried out by open capillary method and were in range of $90-210^{\circ} \mathrm{C}$, IR spectrum was recorded in range of 14000-400 $\mathrm{cm}^{-1}$ and showed characteristic peaks of $\mathrm{NH}$ and of $\mathrm{C}-\mathrm{O}-\mathrm{NH}, 1 \mathrm{H}$ NMR of the compounds was distinct to confirm structures with delta values in the range of 7.53-11.960, Mass spectra proved parent peaks of synthesized compounds confirming molecular weight. The compounds were assayed for antibacterial activity against $S$. aureus and E. coli using ciprofloxacin as standard. The synthesized analogues have shown good yield and comparable antibacterial.
\end{abstract}

Conclusion: The present study delivers a convenient and efficient protocol for the quinazolinone analogues synthesis.

Keywords: Antibacterial, Ciprofloxacin, E. coli, Quinazolinone analogues, S. aureus

(c) 2019 The Authors. Published by Innovare Academic Sciences Pvt Ltd. This is an open access article under the CC BY license (http://creativecommons.org/licenses/by/4.0/] DOI: http://dx.doi.org/10.22159/ijpps.2019v11i11.35461

\section{INTRODUCTION}

Heterocyclic compounds in particularly nitro-heterocyclic compounds contribute staggeringly diverse and equally important class of molecules. The importance of heterocyclic compound in medicinal chemistry is well established, most of the drugs available today contain heterocyclic scaffolds. Quinazolinone scaffold is one of the most important and privileged pharmacophore. Quinazolinones have wide spectrum of their antibacterial, anticonvulsant, antifungal, anticancer, anti-HIV, anti-inflammatory, antitubercular and analgesic activities. Its structure represents capable binding at multiple sites with high affinity and facilitate more rapid discovery of useful medicinally active compounds [1]. There are several approved drugs with quinazoline structure in the market namely alfuzosine, prazosin, terazosine hydrochloride and doxazosine mesylate [2]. In 1860's, the first quinazolinone was synthesized from anthranilic acid and cyanogen to give 2-cynoquinazolinone [3]. In the present research work we have mainly focused on antibacterial activity; because nowadays, worldwide bacterial resistance to available drugs is a growing problem. Antimicrobial agents can benefit in cancer treatment by killing oncogenic-related microorganisms by protecting from recurring immune-suppressioninduced infection and by their direct antiproliferative/cytotoxic effects [4]. Quinazoline possess antibacterial activity against the gram positive strains and fungi through their interaction with cell wall and DNA structure. Early reports for fluorinated compounds conjugated quinazolines conjugated with lysine, 1-[2-(6 nitro-4-oxo2-phenyl-4H-quinazoline) 3yl) ethyl] 3 phenyl urea's, quinazoline imidazoles substituted with amino acids and salicylic acids have shown potent antibacterial activity against E. coli [5-10].
Meena et al. synthesized series of quinazolinone semicarbazone derivatives with 2-isopropyl-5-methylcyclohexan-1-one substitution and nitrophenol which exhibited good anticonvulsant activity. Divyesh et al. synthesized series of $\beta$-aryloxyquinolines, which were investigated against representative panel of pathogenic strains specifically Bacillus subtilis, Clostridium tetani, Streptococcus pneumoniae, Escherichia coli, Salmonella typhi, Vibrio cholera Aspergillus fumigates, Candida albicans and mycobacterium tuberculosis. Compound bearing chloro, methyl and methoxy substitution exhibited comparable potent antifungal, antimicrobial and antitubercular activity. Bhupinder et al. synthesized series of amino acid and peptide derivatives of 5-(2-(2-chlorophenyl)-4oxoquinazolin-3(4H)-yl)-2-hydroxy benzoic acid. The compounds screened for their antimicrobial potential against $S$. pyogenes, $S$ aureus, $P$. aeruginosa, and $E$. coli. All the derivatives have shown promising antimicrobial activity, but the compounds with isopropyl and indole derivatives were having more promising and reproducible effect [11-13].

Priya et al. synthesized series of mannich bases which were screened for anti-oxidant and anti-microbial activity. The compounds with naphthalene derivatives exhibited good antioxidant and antibacterial activity. Niraj et al. synthesized pyrazoline bearing $4(3 \mathrm{H})$-quinazolinone derivatives, which exhibits analgesic and anti-inflammatory activity. The compounds bearing halo and hydroxyl substitution gave comparatively potent analgesic and antiinflammatory activitiy. Megha et al. synthesized quinazolinone derivatives with various substitutions on nitrogen and oxygen derivatives. The compounds exhibited potent activity against DHFR for various human cancer cell lines. Compounds with bromo- 
substitution, tri flouro-methyl group substitution on nitrogen containing ring exhibited comparatively high potency as anticancer agents [14-16].

Prompted by these findings and medicinal importance of quinazolinone we report here the synthesis of novel analogues of 1substituted-3-(4-oxo-2-phenylquinazolin-3(4H)-yl) urea and thiourea derivatives as potential bioactive molecules.

\section{MATERIALS AND METHODS}

Solvents and materials were purchased from Sigma Aldrich Merck and were of synthetic grade. Reaction procedures were optimized on Radley's six station parallel combinatorial synthesizers and monitored on pre-coated aluminum plates (Merck silica gel 60F254) using UV visualization technique and iodine vapors. Melting points (uncorrected) were determined on programmable melting point and boiling point apparatus (VEEGO, India). IR spectra were recorded on JASCO V-530 FTIR 4100. ${ }^{1} \mathrm{H}$ NMR was recorded on "Bruker Avance" Spectrometer at 100, 300, $400 \mathrm{MHz}$ frequency in $\mathrm{CDCl}_{3}$ and DMSO in presence of TMS as internal standard (Chemical shift in ppm). Mass spectra were obtained from G6460A triple quadrupole/MS/MS system (Agilent technologies) equipped with electrospray ionization technique. The In silico drug properties calculation was performed using OSIRIS Data warrior (version 5.0.0.) which is based on Lipinski rule of five. In vitro antibacterial evaluation was carried out against Staphylococcus aureus (NCIM 2079) and Escherichia coli (NCIM 2065) as a microbial strain. (Microbial Strains were obtained from National Centre for Cell Science (NCCS), Pune).

\section{Synthesis of analogues}

On the basis of literature survey and structural activity relationship, six quinazolinone analogues were synthesized $[17,18]$ i.e. SS-A, SSB, SS-01, SS-02, SS-03, SS-04 as depicted in (table 1).

Table 1: Synthesized 1-substituted-3-(4-oxo-2-phenylquinazolin-3(4H)-yl) urea and thiourea analogues

\begin{tabular}{|c|c|c|}
\hline Compound code & Structure & IUPAC name \\
\hline SS-A & $\mathbf{0}$ & 2-phenyl-4H benzo[d][1,3]oxazin-4-one \\
\hline SS-B & & 3-amino-2-phenyl quinazoline-4(3h)-one-4-one \\
\hline SS-01 & & 1-(4-oxo-2-phenylquinazolin-3(4H)-yl)-3-phenylurea \\
\hline SS-02 & & 1-(4-chloro-3-(trifluoromethyl)phenyl)-3-(4-oxo-2-phenylquinazolin-3(4H)-yl)urea \\
\hline SS-03 & & 1-benzyl-3-(4-oxo-2-phenylquinazolin-3(4H)-yl)thiourea \\
\hline SS-04 & & 1-(but-3-en-1-yl)-3-(4-oxo-2-phenylquinazolin-3(4H)-yl)thiourea \\
\hline
\end{tabular}

\section{Step I}

Scheme for synthesis of 2-phenyl-4H benzo[d][1,3]oxazin-4-one (SS-A)

Anthranilic acid solution was prepared by adding $6.85 \mathrm{~g}(0.05 \mathrm{~mol})$ of anthranilic acid to $60 \mathrm{ml}$ of pyridine. To this mixture $5.67 \mathrm{ml}(0.05$ mol) of benzoyl chloride was added drop wise at $0-2^{\circ} \mathrm{C}$ for $2 \mathrm{~h}$. Reaction mixture was stirred for $2 \mathrm{~h}$. The reaction mixture was neutralized with saturated sodium bicarbonate solution and solid product was filtered and re-crystallized from ethanol. The reaction step is depicted in (fig. 1).<smiles>Nc1ccccc1C(=O)O</smiles>

Anthranilic acid

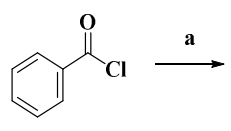

Benzoyl chloride

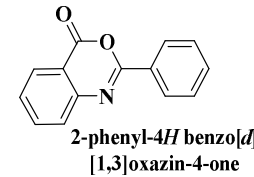

[1,3]oxazin-4-one a: Pyridine

\section{Step II}

Scheme for synthesis of 3-amino-2-phenyl quinazoline-4(3h)one-4-one (SS-B)

$2.2 \mathrm{~g}(0.01 \mathrm{~mol})$ of $4 \mathrm{H}$-benzo[d] [1, 3] Oxazin-4-one was dissolved in ethanol and $0.5 \mathrm{ml}(0.01 \mathrm{~mol})$ of hydrazine hydrate was added to it with catalytic amount of pyridine. Reaction mixture was refluxed for $1 \mathrm{~h}$ and after cooling a crystalline product was filtered and recrystallized from ethanol. The reaction step is depicted in (fig. 2)

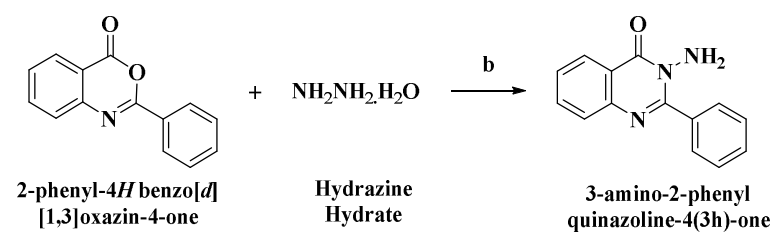

b: Ethanol, Pyridine
Fig. 1: Scheme for synthesis of 2-phenyl-4H benzo[d][1,3]oxazin-4-one (SS-A)
Fig. 2: Synthesis of 3-amino-2-phenyl quinazoline-4(3h)-one-4one 


\section{Step III}

Scheme for synthesis of 1-substituted-3-(4-oxo-2-phenylquinazolin-3(4H)-yl) urea and thiourea analogues

$2 \mathrm{~g}(0.0090 \mathrm{~mol})$ of 3-amino-4H-quinazolinone was dissolved in 10 $\mathrm{ml}$ di-chloro methane (DCM). After stirring the reaction mixture for $5 \mathrm{~min}$ at room temperature $1.99 \mathrm{~g}(0.00900 \mathrm{~mol})$ of respective isocynates were added in it and was stirred. After completion of reaction, product was filtered and re-crystallized from ethanol. The reaction step is depicted in (fig. 3).

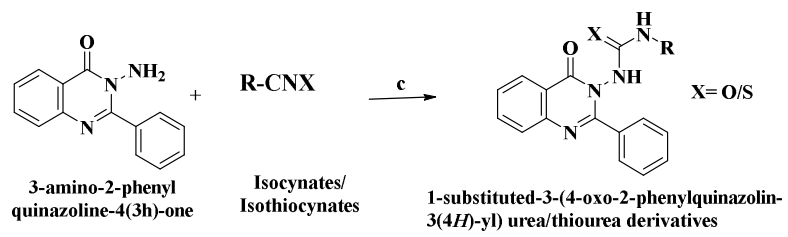

Fig. 3: Scheme for synthesis of 1-substituted-3-(4-oxo-2phenylquinazolin-3(4H)-yl) urea and thiourea analogues

\section{In silico drug properties}

The correlation of absorption, distribution, metabolism, excretion, toxicity and the prediction of physicochemical properties is necessary. For the prediction of physicochemical properties, OSIRIS Data warrior (version 5.0.0.) software was used which is based on Lipinski rule of five [19].

\section{Antibacterial activity}

Antibacterial activity was performed by agar well diffusion method by measuring zone of inhibition. All the test compounds were screened for antibacterial activity against bacterial strains of Staphylococcus aureus (NCIM 2079) and Escherichia coli (NCIM 2065 ) at concentrations of $1000,500,250,125,62.5 \mu \mathrm{g} / \mathrm{ml}$ respectively. Ciprofloxacin was used as standard drug at a concentration of $100 \mu \mathrm{g} / \mathrm{ml}$. Nutrient agar was used as culture medium and DMSO was used as solvent control. Laminar airflow bench was swapped with $70 \%$ alcohol and UV lamp was switched on. After $30 \mathrm{~min}$, the UV lamp was switched off. All the reagents, media, inoculums and glass wares were placed in laminar air flow bench observing all aseptic conditions. The plates were inoculated within minutes of the preparation of suspension, so that the density does not change. A sterile cotton swab over was dipped into the suspension and the medium was inoculated by even streaking of the swab over the entire surface of the plate in three directions. After the inoculums had dried, wells of diameter $6 \mathrm{~mm}$ were made in the agar plate with a sterile cork borer. The drug solutions were added to these wells with a micropipette and the plates were than incubated at $37^{\circ} \mathrm{C}$ for $24 \mathrm{~h}$. The zone of inhibition was measured using $\mathrm{mm}$ scale $[20,21]$.

\section{RESULTS AND DISCUSSION}

\section{Characterization study}

Six quinazolinone derivatives SS-A to SS-04 were synthesized. The yields of final products were obtained in the range of 90-95\%. Recrystallisation was performed using ethanol; TLC was carried out by using toluene: methanol in the ratio 2:1.

The IR spectrum showed characteristic peaks of N-H in range of (3300-3285 $\left.\mathrm{cm}^{-1}\right)$ and of C-0-NH of amide in range of (1640-1687 $\left.\mathrm{cm}^{-1}\right)$. Mass spectra proved parent peaks of the synthesized compounds confirming molecular weight. ${ }^{1} \mathrm{H}$ NMR of the compounds was distinct to confirm structures [22]. Summary of physical constants of synthesized derivatives is depicted in (table 2).

Table 2: Physical constants of synthesized compounds

\begin{tabular}{|c|c|c|c|c|c|}
\hline \multirow[t]{2}{*}{ Code } & \multirow[t]{2}{*}{ Structure } & \multicolumn{4}{|l|}{ Physical constants } \\
\hline & & Melting point $\left({ }^{\circ} \mathrm{C}\right)$ & Yield (\%) & Mol. Formula & $\boldsymbol{R}_{f}$ \\
\hline SS-A & O & $118.0-120.8$ & 95 & $\mathrm{C}_{14} \mathrm{H}_{9} \mathrm{NO}_{2}$ & 0.85 \\
\hline SS-B & & $90.0-93.5$ & 92 & $\mathrm{C}_{14} \mathrm{H}_{11} \mathrm{~N}_{3} \mathrm{O}$ & 0.60 \\
\hline SS- 01 & & $108.5-109.8$ & 90 & $\mathrm{C}_{21} \mathrm{H}_{16} \mathrm{~N}_{4} \mathrm{O}_{2}$ & 0.65 \\
\hline SS- 02 & & $108.5-109.8$ & 95 & $\mathrm{C}_{22} \mathrm{H}_{17} \mathrm{~N}_{4} \mathrm{O}_{2}$ & 0.65 \\
\hline SS- 03 & & $208.5-210.7$ & 91 & $\mathrm{C}_{22} \mathrm{H}_{18} \mathrm{~N}_{4} \mathrm{OS}$ & 0.58 \\
\hline SS- 04 & & $101.5-103.8$ & 95 & $\mathrm{C}_{22} \mathrm{H}_{18} \mathrm{~N}_{4} \mathrm{OS}$ & 0.47 \\
\hline
\end{tabular}




\section{2-phenyl-4H benzo[d][1,3] oxazin-4-one (SS-A)}

IR vmax $\left(\mathrm{cm}^{-1}\right)(\mathrm{KBr}): 3034.44,1764.55,1617.02,1256.4,1518.67$; ${ }^{1} \mathrm{H}$ NMR ( $\delta$, DMSO): 7.53-8.15 (m,-Ar, 9H); ESI-MS $(\mathrm{m} / \mathrm{z})$ for $\mathrm{C}_{14} \mathrm{H}_{9} \mathrm{NO}_{2}$ calculated 223.13 , found 223.19

3-amino-2-phenylquinazolin-4(3H)-one (SS-B)

IR vmax $\left(\mathrm{cm}^{-1}\right)(\mathrm{KBr}): 3355.53,3306.36,1672.95,1590.02 ;{ }^{1} \mathrm{H}$ NMR ( $\delta$, DMSO): 7.53-8.15 (m,-Ar, 9H, s,-NH, 2H); ESI-MS $(\mathrm{m} / \mathrm{z})$ for $\mathrm{C}_{14} \mathrm{H}_{11} \mathrm{~N}_{3} \mathrm{O}$ calculated 237.13 , found 237.19

\section{1-(4-oxo-2-phenylquinazolin-3(4H)-yl)-3-phenyl urea (SS-01)}

IR vmax $\left(\mathrm{cm}^{-1}\right)(\mathrm{KBr}): 3286.11,3032.51,1674.88,1572.66,1504.2$; ${ }^{1} \mathrm{H}$ NMR ( $\delta$, DMSO): 8.5380 (s, 1H, NH), 8.559 (s, 1H, NH), 6.9543$7.9363(\mathrm{~m} 14 \mathrm{H},-\mathrm{Ar})$; ESI-MS $(\mathrm{m} / \mathrm{z})$ for $\mathrm{C}_{21} \mathrm{H}_{16} \mathrm{~N}_{4} \mathrm{O}_{2}$ calculated 356.13, found 356.29

1-(4-chloro-3-(trifluoromethyl)phenyl)-3-(4-oxo-2-phenylquinazolin-3(4H)-yl) urea (SS-02)

IR vmax $\left(\mathrm{cm}^{-1}\right)(\mathrm{KBr}): 3340,1654,1605,1526 ;{ }^{1} \mathrm{H}$ NMR $(\delta$, DMSO):11.86 (s, 1H), 9.39 (s, 1H), 7.522-8.670 (m, 12H); ESI-MS $(\mathrm{m} / \mathrm{z})$ for $\mathrm{C}_{22} \mathrm{H}_{17} \mathrm{~N}_{4} \mathrm{O}_{2}$ calculated 458.08 , found 458.49
1-benzyl-3-(4-oxo-2-phenylquinazolin-3(4H)-yl) thiourea (SS03)

IR vmax $\left(\mathrm{cm}^{-1}\right)(\mathrm{KBr}): 3204.15,2933.21660 .14,1602.56,1520.16$ 1H NMR ( $\delta$, DMSO):11.960 (s, 1H,-NH), 10.738 (s, 1H,-NH), 4.721(t, $\left.2 \mathrm{H},-\mathrm{CH}_{2}-\right)$, 7.185-8.772 (m, $\left.14 \mathrm{H},-\mathrm{Ar}\right)$; ESI-MS $(\mathrm{m} / \mathrm{z})$ for $\mathrm{C}_{22} \mathrm{H}_{18} \mathrm{~N}_{4} \mathrm{OS}$ calculated 386.12 , found 386.14

1-(but-3-en-1-yl)-3-(4-oxo-2-phenylquinazolin-3(4H)-yl) thiourea (SS-04)

IR vmax $\left(\mathrm{cm}^{-1}\right)(\mathrm{KBr}): 3274.54,3023,2950.55,2845.45,1684.52$, 1602, 1534.11, 1447.31; 1H NMR ( $\delta$, DMSO):11.960 (s, 1H,-NH), $10.738(\mathrm{~s}, 1 \mathrm{H},-\mathrm{NH}), 3.95\left(\mathrm{t}, 2 \mathrm{H},-\mathrm{CH}_{2}-\right), 7.185-8.772$ (m, 9H,-Ar); ESIMS $(m / z)$ for $\mathrm{C}_{22} \mathrm{H}_{18} \mathrm{~N}_{4} \mathrm{OS}$ calculated 350.12 , found 350.44

\section{In silico drug likeness}

The compounds were screened physicochemical properties and drug toxicity. All compounds have shown less toxicity risks, with no violation for Lipinski rule of five. Less solubility of the synthesized compound was predicted and was observed practically. The compounds were screened for antibacterial activity on the basis of drug likeness score as shown in the (table 3 ).

Table 3: OSIRIS calculation for lipinski rule of five

\begin{tabular}{|c|c|c|c|c|c|c|c|}
\hline Code & Mol. weight & cLogP & cLogS & H-acceptors & H-donors & Drug likeness & Drug score \\
\hline SS-A & 223.13 & 0.351 & -3.341 & 3 & 0 & 4.81418 & 0.571266 \\
\hline SS-B & 237.13 & 0.8997 & -3.061 & 4 & 1 & 5.77379 & 0.598914 \\
\hline SS-01 & 356.13 & 2.5345 & -4.389 & 5 & 1 & 0.2575 & 0.321117 \\
\hline SS-02 & 458.08 & 3.9888 & -5.903 & 5 & 1 & 2.8979 & 0.716608 \\
\hline SS-03 & 386.13 & 2.5326 & -4.354 & 5 & 1 & 0.35094 & 0.316608 \\
\hline SS-04 & 350.12 & 2.1636 & -3.716 & 4 & 1 & 2.8868 & 0.716708 \\
\hline
\end{tabular}

Table 4: Antibacterial activity of synthesized compounds against $S$. aureous and $E$. coli in terms of zone of inhibition in $\mathrm{mm}$

\begin{tabular}{|c|c|c|c|c|c|c|c|c|c|c|}
\hline \multirow{3}{*}{$\begin{array}{l}\text { Compound } \\
\text { code } \\
\text { conc. }\end{array}$} & \multicolumn{10}{|c|}{ Zone of inhibition $(\mathrm{mm}) \pm$ Std deviationa } \\
\hline & \multicolumn{5}{|l|}{ S. aureus } & \multicolumn{5}{|l|}{ E. coli } \\
\hline & $\begin{array}{l}1000 \\
\mu \mathrm{g} / \mathrm{ml}\end{array}$ & $\begin{array}{l}500 \\
\mu \mathrm{g} / \mathrm{ml}\end{array}$ & $\begin{array}{l}250 \\
\mu \mathrm{g} / \mathrm{ml}\end{array}$ & $\begin{array}{l}125 \\
\mu \mathrm{g} / \mathrm{ml}\end{array}$ & $\begin{array}{l}62.5 \\
\mu \mathrm{g} / \mathrm{ml} \\
\end{array}$ & $\begin{array}{l}1000 \\
\mu \mathrm{g} / \mathrm{ml}\end{array}$ & $\begin{array}{l}500 \\
\mu \mathrm{g} / \mathrm{ml}\end{array}$ & $\begin{array}{l}250 \\
\mu \mathrm{g} / \mathrm{ml}\end{array}$ & $\begin{array}{l}125 \\
\mu \mathrm{g} / \mathrm{ml} \\
\end{array}$ & $\begin{array}{l}62.5 \\
\mu \mathrm{g} / \mathrm{ml}\end{array}$ \\
\hline $\begin{array}{l}\text { Std } \\
\text { (Ciprofloxacin) }\end{array}$ & -- & $36.00 \pm 1.00$ & $34.00 \pm 2.00$ & $39.33 \pm 1.15$ & $27.67 \pm 2.08$ & -- & $26.00 \pm 1.00$ & $34.00 \pm 2.00$ & $25.33 \pm 1.15$ & $21.00 \pm 1.00$ \\
\hline Control & -- & -- & -- & -- & -- & -- & -- & -- & -- & -- \\
\hline SS-A & $11.00 \pm 1.25$ & $10.00 \pm 2.00$ & $8.33 \pm 1.15$ & $6.67 \pm 2.08$ & $0.00 \pm 0.00$ & $11.33 \pm 2.00$ & $9.33 \pm 1.15$ & $7.67 \pm 2.08$ & $6.00 \pm 1.00$ & $0.00 \pm 0.00$ \\
\hline SS-B & $10.00 \pm 1.25$ & $8.00 \pm 2.00$ & $6.33 \pm 1.15$ & $5.67 \pm 2.08$ & $0.00 \pm 0.00$ & $10.25 \pm 2.00$ & $8.33 \pm 1.15$ & $6.67 \pm 2.08$ & $4.00 \pm 1.00$ & $0.00 \pm 0.00$ \\
\hline SS-01 & $5.00 \pm 1.25$ & $4.52 \pm 1.15$ & $4.12 \pm 2.08$ & $0.00 \pm 0.00$ & $0.00 \pm 0.00$ & $4.52 \pm 1.15$ & $4.12 \pm 2.08$ & $3.00 \pm 1.15$ & $2.00 \pm 2.08$ & $0.00 \pm 0.00$ \\
\hline SS-02 & $16.00 \pm 1.25$ & $15.67 \pm 1.00$ & $11.33 \pm 1.15$ & $10.67 \pm 2.08$ & $0.00 \pm 0.00$ & $13.00 \pm 1.25$ & $12.00 \pm 1.00$ & $11.00 \pm 1.15$ & $9.00 \pm 2.08$ & $0.00 \pm 0.00$ \\
\hline SS-03 & $9.01 \pm 1.25$ & $7.01 \pm 2.00$ & $4.52 \pm 1.15$ & $4.12 \pm 2.08$ & $0.00 \pm 0.00$ & $4.52 \pm 1.15$ & $4.12 \pm 2.08$ & $0.00 \pm 0.00$ & $0.00 \pm 0.00$ & $0.00 \pm 0.00$ \\
\hline SS-04 & $17.57 \pm 1.25$ & $16.57 \pm 2.00$ & $14.67 \pm 1.15$ & $12.00 \pm 2.08$ & $0.00 \pm 0.00$ & $11.00 \pm 1.25$ & $11.00 \pm 2.00$ & $12.00 \pm 1.15$ & $10.00 \pm 2.08$ & $0.00 \pm 0.00$ \\
\hline
\end{tabular}

A: each value is the mean of three values.

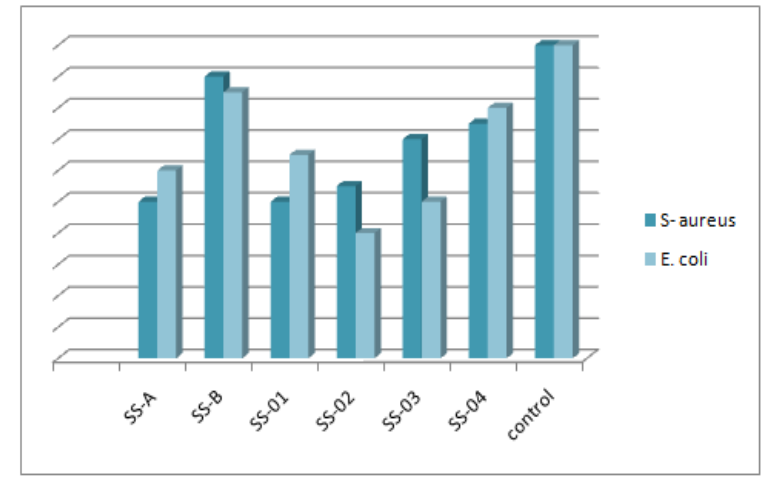

$\mathrm{X}$ axis : Concentration $500 \mu \mathrm{g} / \mathrm{ml} \mathrm{Y}$-axis : Microbial inhibition in $\mathrm{mm}$

Fig. 4: Comparative zone of inhibition of synthesized compounds

\begin{abstract}
Antibacterial evaluation
All six synthesized analogues bearing various substitutions were screened for antibacterial activity. All the compounds have shown significant activity at $500 \mu \mathrm{g} / \mathrm{ml}$ for $S$. aureus and E. coli. The summary of antibacterial activity is shown in the (fig. 4 and table 4).

\section{CONCLUSION}

In the proposed research work an attempt was made to synthesize novel quinazolinone analogues by considering the substitution pattern on quinazolinone moiety as microbial inhibitors. The study performed includes various aliphatic and aromatic substitutions on the nitrogen of quinazolinone. All the synthesized compounds were confirmed by IR, NMR and Mass Spectrometry. These synthesized compounds were evaluated for preliminary antibacterial activity. Amongst the six analogues SS-02 and SS-04 have shown comparable against $S$. aureus and E. coli using Ciprofloxacin as standard. Thus the result reveals that the synthesized analogues may be used for designing of novel antibacterial agents.
\end{abstract}




\section{DISCUSSION}

In the present study we have synthesized quinazolinone derivatives with 1-substituted-3-(4-oxo-2-phenylquinazolin-3(4H)-yl) urea and thiourea. The compounds exhibited comparable antibacterial activity. The reported literature of quinazolinone with substitutions of chloro, methyl, methoxy, hydroxyl, ethers, thioethers,1-chloro-2(trifluoromethyl) benzene and N-but-3-ene thiourea derivatives exhibited good antibacterial and anticancer activity [23-28]. When we compared our synthesized derivatives with them we could find a new target wherein we can structurally modify our derivatives to develop new series of quinazolines with antibacterial as well as anticancer activity.

\section{ACKNOWLEDGMENT}

The authors are thankful to Centre of Food Testing, Bharati Vidyapeeth (Deemed to Be University), Pune for providing LC-MS services, SPPU, Pune for providing NMR facility and Principal, Poona College of Pharmacy, Pune for providing infrastructure and support to carry out the proposed research work.

\section{AUTHORS CONTRIBUTIONS}

Deepali A Bansode conceived the idea, supervised the experiments, analyzed the results and drafted the manuscript. Sandhya R Dhokale and Snehal $\mathrm{R}$ Thakar have contributed as research associate in performing experiments. Kakasaheb $\mathrm{R}$ Mahadik contributed in carrying out research work by providing the essential infrastructure.

\section{CONFLICT OF INTERESTS}

The authors declare that there is no conflict of interests regarding the publication of this research article.

\section{REFERENCES}

1. Samira I, Patel S, Hasmin M, Patel S. Biological profile of quinazoline. Int J Pharm Chem Sci 2012;1:1863-72.

2. Jafari E, Khajouei MR, Hassanzadeh F, Hakimelahi GH, Khodarahmi GA. Quinazolinone and quinazoline analogues: recent structures with potent antimicrobial and cytotoxic activities. Res Pharm Sci 2016;1:1-14.

3. Schroeder LA, Gries TJ, Saecker RM, Record Jr MT, Harris ME, de Haseth PL. Evidence for a tyrosine-adenine stacking interaction and for a short-lived open intermediate subsequent to initial binding of Escherichia coli RNA polymerase to promoter DNA. J Mol Biol 2009;16:339-49.

4. Zhang K, Lai F, Lin S. Design, synthesis and biological evaluation of 4-methyl quinazoline derivatives as anticancer agents simultaneously targeting phosphoinositide 3-kinases and histone deacetylases. J Med Chem 2019;62:6992-7014.

5. Muthu K, Madhavi M, Kiana N, Aparna S, Kishor S. Topoisomerase as a target for antibacterial and anticancer drug discovery. J Enzyme Inhib Med Chem 2013;28:419-35.

6. Mohamed M, Ghanem H, Abd F, Mohamed S. Biological evaluation and molecular docking of substituted quinazolinones as antimicrobial agents. Aust J Basic Appl Sci 2013;7:263-74.

7. Suresha P, Prakasha C, Kumara S, Kapfo W, Gowda C. Design and synthesis of heterocyclic conjugated peptides as novel antimicrobial agents. Int J Pept Res The 2009;15:25-30.

8. Rana M, Desai R, Jauhari S. Synthesis, characterization, and pharmacological evaluation of 1-[2-(6-nitro-4-oxo-2-phenyl-4Hquinazolin-3-yl)-ethyl]-3-phenyl ureas. Med Chem Res 2013;22:225-33.

9. Olomola 0, Akinpelu A, Obafemi A. Microwave-assisted synthesis and antibacterial activity of some quinazolinone analogues. J Pharm Res 2013;6:6337.
10. Zeinyeh W, Esvan J, Josselin B. Kinase inhibitions in pyrido[4,3h] and [3,4-g]quinazolines: Synthesis, SAR and molecular modeling studies. Bioorg Med Chem 2019;27:2083-9.

11. Yadav MK, Tripathi L, Goswami D. Synthesis and anticonvulsant activity (Chemo shock) of N-1(substituted-n-4[(4-oxo-3phenyl-3, 4-dihydro-quinazoline-2-ylmethyl) semicarbazones. Asian J Pharm Clin Res 2017;10:359-66.

12. Mungra DC, Patel MP, Rajani DP, Patel RG. Synthesis and identification of $\beta$-aryloxyquinolines and their pyrano[3,2-c] chromene derivatives as a new class of antimicrobial and antituberculosis agents. Eur J Med Chem 2011;46:4192-200.

13. Kapoor B, Nabi A, Gupta R, Gupta M. Synthesis and antimicrobial evaluation of quinazolinone peptide derivatives. Asian J Pharm Clin Res 2017;10:7-12.

14. Priya D, Srimathi R, Anjana GV. Synthesis and evaluation of some mannich bases of quinazolinone nucleus. Asian J Pharm Clin Res 2018;11:407-9.

15. Niraj Kumar Sinha, Alpana J Asnani. Novel approach towards development of quinazoline derivatives in pain management. Asian J Pharm Clin Res 2013;6:200-4.

16. Megha Sahu, Amit G Nerkar. In silico screening, synthesis and in vitro evaluation of some quinazolinone derivatives as dihydrofolate reductase inhibitors for anticancer activity: PartI. Int J Pharm Pharm Sci 2014;6:193-9.

17. Dahiya R, Kumar A, Yadav R. Synthesis and biological activity of peptide analogues of iodoquinazolinones/nitroimidazoles. Molecules 2008;13:958-76

18. Rajveer CH, Kumaraswamy S, Rathinaraj SB. Synthesis of some 6-bromo quinazolinone analogues for their pharmacological activities. Int J Pharma Bio Sci 2010;2:50-6.

19. Messali M, Aouad MR. Synthesis, characterisation and POM analysis of novel bioactive imidazolium-based ionic liquids. Med Chem Res 2015;24:1387-95.

20. Gemma S, Camodeca C, Brindisi M. Mimicking the intramolecular hydrogen bond: synthesis, biological evaluation, and molecular modeling of benzoxazines and quinazolines as potential antimalarial agents. J Med Chem 2012;55:10387-404.

21. Balouiri M, Sadiki M, Ibnsouda SK. Methods for in vitro evaluating antimicrobial activity: a review. J Pharm Anal 2016;6:71-9.

22. Pavia D, Lampmanh $\mathrm{H}$, Kvizgeorge. Introduction to Spectroscopy. $3^{\text {rd }}$ ed.: Cengage Learning; 2017.

23. Zhijiang Fan. Synthesis, crystal structure and agricultural antimicrobial evaluation of novel quinazoline thioether derivatives incorporating the 1,2,4-triazolo[4,3-a]pyridine moiety. J Agric. Food Chem 2019;67:1-37.

24. Buggana S, Paturi M, Perka H, Gade D, VVS R. Novel 2,4disubstituted quinazolines as cytotoxic agents and JAK2 inhibitors: synthesis, in vitro evaluation and molecular dynamics studies, comput. Biol Chem 2019;153:39-47.

25. Karuna S, Naresh P, Katari K, Jonnalagadda S. Design and synthesis of novel 6-substituted quinazoline-2-thiols. Mol Divers 2019;23:351-60.

26. Jacob B, Bisht L, Chandy V. 3D QSAR studies of 2, 3disubstituted quinazoline phenyl acetic acid derivatives as antimicrobial agents. Res Rev: J Pharm Sci 2018;79:110-8.

27. Chen J, Sang Z, Jiang Y, Yang C, He L. Design, synthesis and biological evaluation of quinazoline derivatives as dual HDAC1 and HDAC6 inhibitors for the treatment of cancer. Chem Biol Drug Des 2019;93:232-41.

28. Faghihi K, Safakish M, Zebardast T, Hajimahdi Z, Zarghi A. Molecular docking and QSAR study of 2-benzoxazolinone, quinazoline and diazocoumarin derivatives as anti-HIV-1 agents. Ira J Pharm Res 2019;18:1253-63. 